\title{
La literatura de migración entre la chicana y la fronteriza
}

\author{
Fatema Mohamed El Shamly \\ Facultad de Al-Alsun, Universidad de Kafrelsheikh, Egipto \\ ftmaselim2000@gmail.com
}

Received: February 13, $2021 \quad$ Accepted: April 5, $2021 \quad$ Published: June 30, 2021

Owing to the great demographic changes that are now taking place in the world, Czech literature and border literature have recently become the focus of many studies. This is precisely due to the endless number of Latinos immigrating to the US for many reasons; either they might immigrate for political reasons, or for social reasons such as the desire to improve their standard of living, believing that the US is the dreamland where all problems are solved. This phenomenon has affected both societies, the homeland of immigrants and their recipient as well as the literature written by both of them. Accordingly, we cannot address the issue of Latin immigration to the US without presenting these two types of literature (Czech and border literature). Hence, this paper is aimed at studying this type of literature and the characteristics it displays that make it apt to belong to both Czech and border literature. The paper also presents the origin and reasons for naming both Czech literature and border literature, the distinguishing features of each, how each type originated, where and when it appeared, and identifying the differences between them. To do so, the two novels. Eduardo González Viaña's Dante's Ballad and Carlos Fuentes's The Crystal Frontier have been chosen as models.

Keywords immigration, borders, Czech literature, border literature, Mexico, USA 


\section{Resumen}

La literatura chicana y la literatura fronteriza disfrutan, hoy en día, de una notable difusión debido al gran número de emigración por parte de los ciudadanos de países de América Latina a los Estados Unidos. Por eso, muchos estudios consideran a estos dos tipos de literatura como una manifestación cultural. El objetivo principal de este artículo es acercarnos a dichos movimientos haciendo hincapié en su denominación, surgimiento y rasgos generales. También pretendemos identificar las diferencias que existen entre la escritura chicana y la escritura fronteriza, presentando como modelos El corrido de Dante, de Eduardo Gonzales Viaña y La frontera de cristal, de Carlos Fuentes.

Palabras clave: literatura chicana, literatura fronteriza, frontera, México, Estados Unidos

\section{Introducción}

Últimamente, hay un gran interés por ciertos tipos de literatura debido a los grandes y rápidos cambios que sufre nuestro planeta. Entre estos cambios se destacan las guerras y las difíciles condiciones económicas que modificaron la demografía del mundo. Millones de personas se ven obligadas a dejar su patria por diferentes motivos, especialmente los árabes y los latinos. Como consecuencia, surgieron la literatura chicana y la fronteriza. No podemos abordar el tema de la inmigración sin hablar de la literatura chicana, cuya comprensión depende de la profunda reflexión del chicano y su condición en el país de acogida, en este caso, Estados Unidos.

\section{Denominación}

Como consecuencia del gran número de inmigrantes mexicanos en Estados Unidos, surgió la "literatura chicana", un tipo de literatura que versa sobre la vida de éstos. Es la literatura de escritores mexicanos o hijos de mexicanos residentes en Estados Unidos. "El término también incluye los escritores latinos residentes en Estados Unidos quienes abordan la temática social y racial de la minoría latinoamericana" (Rodríguez Ortiz, 2008, p. 113). Por otra parte, presenta la identidad mexicana y su ideología. 
La literatura chicana se considera un denunciador de la reacción de la sociedad estadounidense contra el otro y una presentación de la identidad de los latinos. Los habitantes del suroeste de los Estados Unidos cultivan una literatura que se califica como chicana dirigida al mundo hispanohablante.

El término chicano apareció en el siglo veinte, a mediados de la década de los cincuenta. El chicano es la persona de origen mexicano residente en Estados Unidos, o sea, un estadounidense que cuenta con padres o antepasados mexicanos. El sujeto chicano tiene la particularidad de ser concebido a través del insulto, de la violencia, de la opresión y de la dominación cultural. A veces este término se asume para indicar a un ciudadano de segunda categoría. (Rodríguez Ortiz, 2008, p. 115)

No se sabe con certeza el origen de la palabra "chicano". Algunos creen que la palabra desciende de la palabra mexicano, cuando otros devuelven el término a la palabra chico o es mezcla entre los dos:

Otras etimologías parecen indicar una posible procedencia de 'chico' (uso paralelo al boy utilizado para los negros) y el sufijo '- ano' como en 'mexicano' o 'americano.' Incluso se ha especulado con que hubiera resultado de la mezcla de mexicano de Chihuahua [chi + cano]. Este término también puede deberse a la metátesis de la voz indígena que significa "desnudo; gente desarrapada" [xinaca > chinaca]. (Arévalo Fernández, 2010, p. 73)

Aunque los mexicanos que están en el norte de Estados Unidos se consideran estadounidenses a partir de la guerra entre México y Estados Unidos, que terminó con la firma del tratado de Guadalupe 1848, que afirmó la soberanía de Estados Unidos sobre seis ciudades mexicanas, no se miraban como ciudadanos estadounidenses completamente. De esta manera, los chicanos, históricamente, son la minoría más antigua y la más reciente en Estados Unidos.

Estas personas son, por ley, estadounidenses, pero el color de su piel, su lengua y sus tradiciones impidieron su integración a la sociedad estadounidense. Los mismos chicanos llaman "chicanos" a las personas que pertenecen a las clases bajas. Por eso, la mayoría de los chicanos rechazan la palabra chicano para identificarlos. Prefieren nombres que expresan su procedencia. En cuanto a la literatura fronteriza, es un término que se refiere a la de los estados fronterizos de Estados Unidos que se conoce como border literature, según afirma Socorro Tabuenca: "Debido a que la mayoría de las veces se refiere más a conceptos que a 
una región geográfica" (Tabuenca Córdoba, 1997, p.8).

A la hora de pensar en el significado de la literatura fronteriza surgen varias interrogaciones como: esta literatura $i s e$ refiere a la frontera del lado mexicano, a la frontera del lado estadounidense o ambas fronteras a la vez? ¿Indica a la producción literaria que trata de la frontera? ¿Cuál es el tipo de las historias contadas? ¿Quiénes son los escritores que viven en la frontera? ¿Está relacionada esta literatura con los escritores nacidos en la frontera o sus obras son los que reflejan la frontera incluso si el escritor no vive en la frontera? Debemos reconocer la complejidad del significado del término. Hay varias opiniones. Algunos ven que el término de la literatura fronteriza indica a los escritores nacidos en baja California incluso si dicha escritura no expresa del tema fronterizo:

Se entiende por literatura de la frontera aquella literatura escrita por autores nacidos o radicados en alguno de los puntos de la frontera mexicana. Sus temáticas, los escenarios, personajes y lenguajes pueden o no corresponder al entorno fronterizo. Lo que importa apuntar es el lugar de nacimiento o residencia de los escritores, y no tanto la filiación cultural de su obra. (Tabuenca Córdoba, 1997, p. 87)

Otro punto de vista plantea el término para identificar la literatura que expresa acciones ocurridas en los seis estados que tienen fronteras con Estados Unidos (Tijuana, Chihuahua, Mexicali, Tecate, Ensenada y Rosarito):

Cuando se habla de literatura de la frontera se entiende por ella a la literatura de la región que comprende a los seis estados fronterizos del norte que colindan con Estados Unido, y entonces el concepto se podría extender para incluir en él otros puntos de la geografía norteña (Hermosillo, Chihuahua, Monterrey, Saltillo). Incorporando libremente escritores que no residen en la franja fronteriza, pero que resultan importantes en el balance de la literatura producida en el norte mexicano. (Torres Sauchett, 2013, p. 180)

Algunos la definen como la literatura que se escribe y se publica desde la frontera: "Otra consideración es la que toma en cuenta aquella literatura que se escribe, se publica y se difunde desde la frontera misma" (Torres Sauchett, 2013, p. 180). No estamos de acuerdo con esta opinión porque no es necesariamente todas las obras escritas desde la frontera se publican y se difunden desde la frontera. Mientras que otros consideran que es todo lo que nos presenta el tema de la frontera generalmente: 
La literatura de la frontera es aquella literatura en la que se aborda algún tema fronterizo. Esto es, aquella literatura que da cuenta de la vida social en cualquiera de las ciudades y regiones fronterizas del norte del país [...] en cuyo caso hablaríamos de la literatura de y sobre la frontera. (Torres Sauchett, 2013, 181)

Otra definición de la literatura de frontera es "un movimiento sociopolítico, como una respuesta a la tensión existente entre el centro y el margen, entre las voces autorizadas y las subversivas y no tanto como una pieza literaria más del vasto paisaje de la literatura mexicana" (Torres Sauchett, 2013, p.181).

De esta forma, según nuestra comprensión, la literatura fronteriza es la literatura del norte de México redactada por escritores mexicanos residentes en México, que encarnan o narran la historia de los personajes ficticios y su sufrimiento en la frontera, la nostalgia, la violencia, etc. El estudio de este tipo de literatura se empezó en los años ochenta del siglo XX. Está cementada en presentar la frontera con todo lo que lleva.

\section{Rasgos generales}

\subsection{La literatura chicana}

La literatura chicana se caracteriza por narrar las experiencias de los estadounidenses latinos, ya sean inmigrantes o nativos de primera generación o de aquellas comunidades de habla hispana en los estados de Texas, Nuevo México, Arizona y California cuando pertenecían al imperio mexicano. Es una literatura que presenta un rasgo bicultural: lo anglosajón y lo hispano. Tuvo mucho interés, tanto por parte del ámbito cultural estadounidense como el internacional.

Esta literatura, a su vez, pone de manifiesto temas y preocupaciones propios de la comunidad mexicana-americana, entre ellos: la falta de oportunidades en la educación, la carencia de participación política, así como los problemas generados por motivos de raza y etnia; y la lucha de este pueblo para confirmar su identidad, influenciada por el contexto histórico que los ha rodeado. La literatura chicana se escribe en inglés puro, en español o en mezcla entre ambas lenguas. Una de las características de la literatura chicana escrita en inglés, desde sus orígenes hasta el presente, es la presencia de palabras y frases españolas en el texto, un rasgo patente en las obras de María Ruiz de Burton como 
Don Quixote de la Mancha, 1876.

Los mexicanos que lleva la nacionalidad americana deseaban integrarse más en la sociedad americana, por eso se nota que los autores antes de los años 60 escribían en inglés, porque no conocían la lengua de sus padres y abuelos. Pero en los años 60 volvieron a escribir en español.

Los autores anteriores al movimiento de los sesenta escriben en inglés, muchos de ellos por la simple razón de que desconocían la lengua de sus padres o abuelos. El establecimiento en 1969 de la Editorial Quinto Sol representa un gran adelanto en la producción y la distribución de la literatura, que ahora se vuelve a escribir en español también. No menos importante fue el establecimiento de los premios Quinto Sol para autores chicanos que escribieran ya en español, ya en inglés. (Torres Sauchett, 2013, p.116)

Durante el siglo XX ocurre un renacimiento en el uso del español, tanto entre el pueblo (con la llegada al suroeste de miles de inmigrantes mexicanos), como en la literatura, por medio de la presencia de escritores exiliados, quienes fundaron periódicos y editoriales, y contribuyeron con sus propias obras. La primera generación hablaba español puro mientras la segunda usaba el inglés fuera de la casa y el español dentro de la misma, pero la tercera casi empezó a mezclar las dos lenguas; y la cuarta usó el espanglish en la calle y en casa. Otro factor igualmente significativo es la edad y la educación.

Un barrio a las afueras de Alburquerque, Nuevo México, que por sus características parece un pueblo rural, puede servirnos de ejemplo. Aquí donde el inglés es la lengua profesional y el español la lengua de casa, el español es la lengua materna de los mayores de 25 años y entre el grupo que aún no ha cumplido los 25 años, una tercera parte tiene el inglés como lengua materna, otra tercera parte el español y el otro tercio bilingüe. (Hudson-Edwards \& Bills, 1980, p.137)

Otro factor muy importante también es la cuestión geográfica. En las ciudades, los chicanos hablan inglés mientras que en los pueblos de chicanos se habla español. Otro punto que se debe tener en cuenta es el cambio de la situación económica y el prestigio de las lenguas. Las nuevas generaciones creen que el inglés da gran prestigio. El español chicano se habla en algunos lugares que es poco diferente del español original de los exploradores de América Latina:

En el sudoeste de los EE-UU. Hay cuatro zonas dialectales: (1) Texas, (2) Nuevo México y el sur de Colorado, (3) Arizona y (4) California. De acuerdo 
con consideraciones diacrónicas existen dos españoles, uno de los cuales —el más arcaico New Mexican Spanish 15- corresponde y coincide con el de los exploradores y colonizadores que habitaron el sur de Colorado y el norte de Nuevo México. El otro español sería el que se habla en el resto de la región en la que habita la comunidad chicana, y que coincide con inmigraciones posteriores. (Cardenas, 1970, p.124)

\subsection{La literatura fronteriza}

Este tipo de literatura se caracteriza por la presentación del espacio urbano que está creciendo de una manera acelerada. También la literatura fronteriza es una manera de protesta, ya que se trata temas de política.

Literatura de la frontera norte de México" o "literatura fronteriza" estaba conformada por los/las escritores/as nacidos o radicados en los seis estados fronterizos e incluso en otras ciudades norteñas, como Hermosillo, Chihuahua, Monterrey o Saltillo, cuyas temáticas se relacionan y se gestan y desde la frontera. En este sentido, una de las características principales de la literatura de la frontera norte de México es la representación del espacio urbano. (Cardenas, 1970, p.20)

La literatura fronteriza refleja el choque entre dos realidades contradictorias, dos culturas, dos sociedades, dos políticas y dos economías, las del país original y las del país receptor. Por eso, buena parte de estas escrituras muestran la problemática resultada de este encuentro contradictorio entre la riqueza y la pobreza, la opresión y la libertad, la democracia y la dictadura, el desarrollo, la decadencia y el analfabetismo, y el nivel alto de educación.

La literatura fronteriza describe el desierto, el mar, el río Bravo y el muro entre los dos países. Es difícil identificar una sola definición de la literatura fronteriza, es un ámbito abierto para la investigación.

El término literatura de Frontera es difícil de formular dada la multiplicidad de sentidos que irradia. Ciertamente quedan abiertos algunos frentes para investigaciones ulteriores. Por eso no solamente es válido sino también necesario seguirse cuestionando en qué consiste este movimiento literario gestado en la frontera norte de México. (Cardenas,1970, p. 124)

La literatura fronteriza es una literatura regional, es decir, hay una relación coherente entre el escritor y la región que toma sus características de dicha región. Uno de los temas importantes que aborda la literatura fronteriza es la diferencia entre dos tiempos y dos espacios de dos países distintos, México y Estados Unidos. Por lo tanto, se ofrece comparaciones entre dos países en las leyes, el sistema de vida, las 
oportunidades, etc. Del mismo modo, la ciudad es espacio planteado abundantemente en la literatura fronteriza.

La ciudad es una parte del sistema representado por el imaginario social que conjuga sus elementos para recrear la escenografía que permite dramatizar las historias narradas en/desde la frontera, pues la ciudad se erige como un "territorio retórico": "un espacio donde cada uno se reconoce en el idioma del otro, y hasta en los silencios." (Augé, 2006, p.128)

\section{Surgimiento}

La literatura chicana empezó oralmente, cuyos temas eran religiosos o corridos $^{1}$

Desde 1767 hasta mediados del siglo XIX, periodo de despoblamiento, ruina de las misiones y retroceso social, las principales expresiones líricas fueron los cantares populares, especialmente los corridos, dedicados a relatar las hazañas y avatares de los bandoleros mexicanos en la Alta California. (Torres Sauchett, 2013, p. 109)

Más tarde, se narran las costumbres y las creencias mexicanas. Por eso, a sus inicios, era lógico encontrar símbolos míticos en las obras que pertenecen a la literatura chicana, que se matizaban con los mitos, la cultura indígena o los símbolos religiosos como La Virgen de Guadalupe donde se tronza de lo material y lo espiritual. Pero, a partir de los años setenta, esta tradición se dejó de cultivar.

A finales de los setenta, la literatura chicana deja de lado la influencia indigenista del México posrevolucionario y, en muchos casos, también los símbolos míticos a partir de los cuales se identificaron como comunidad (la Virgen, los volcanes, Aztlán). En su lugar, los/las escritores/as empiezan a jugar con los espacios y las formas para establecer puentes entre sus culturas, que les permitan transitar libremente entre un lado y otro. (Aranda Oller, 2002, p.60)

Tanto la literatura chicana como la fronteriza nacieron a la sombra de los conflictos entre Estados Unidos y México por la tierra. Ambos tipos son el resultado de un conjunto de procesos y culturales, entre los cuales se destaca la Guerra de Intervención Norteamericana, la guerra que duró dos años, de 1846 a 1848 y se acabó con la firma del Tratado de Guadalupe que fue firmado al final de la guerra por los gobiernos de México y los Estados Unidos el 2 de febrero de 1848, y fue ratificado el 30 de mayo de

\footnotetext{
${ }^{1}$ Corrido: es un tipo musical en México que narra la historia de un personaje real o ficticio. (nota del investigador).
} 
1848. El tratado consistió en que México rendiría más de la mitad de su territorio, que comprende la totalidad de lo que hoy son los estados de California, Nevada, Utah, Nuevo México, Texas, partes de Arizona, Colorado, Wyoming, Kansas y Oklahoma. Además, México dimitiría a todo reclamo sobre Texas y la frontera internacional se establecería en el Río Bravo.

El convenio renovaba el anterior de Amistad y Comercio y establecía la forma de resolver diferencias que podrían suscitarse en el futuro, además de una nueva frontera mexicana en su artículo $\mathrm{V}$ y, en los 1II y IV, los términos de evacuación de tropas y la devolución de instalaciones ocupadas. (Barboto, 1999, p.19)

En el tratado de Guadalupe Hidalgo, se hablaron sólo de la tierra, pero nunca de la lengua. "Si bien en el Artículo IX del Tratado se dice que los mexicanos que decidieran quedarse podían conservar su religión, no se menciona la lengua" (Del Castillo, 1990, p.190). Baja California es una de las regiones que sufrió gran cambio territorial. Ya que después de la guerra entre México y Estados Unidos, que se acabó por la firma del tratado de Guadalupe, California se dividió en dos partes, baja California en México y alta California en Estados Unidos. "La Alta California, territorio perdido en 1848 con el "Tratado de Guadalupe Hidalgo"; y la Baja California, situada actualmente del lado mexicano, que abarca todo el territorio de la península del mismo nombre" (Portes, 2006, p.187).

Como consecuencia de estas condiciones, apareció la literatura que refleja esta región, la llamada literatura bajacaliforniana que forma parte de la literatura fronteriza:

La literatura bajacaliforniana actual forma parte de la Literatura de la Frontera y al igual que cada una de las regiones fronterizas del norte de México tiene sus propios antecedentes, su historia y sus peculiaridades culturales, cuyo desarrollo sobresale a partir de 1970. (Portes, 2006, p.187)

Estas condiciones causaron al final un flujo migratorio. Los mexicanos no la consideraban migración con todo lo que lleva la palabra, sino una vuelta a sus tierras originales y de aquí surgió la literatura fronteriza que encarna el sufrimiento de los inmigrantes. De esta forma, se puede observar que la pérdida de las tierras inicia ambos tipos de literatura chicana y fronteriza. 
Los literarios e historiadores no están de acuerdo con lo que corresponde al inicio de la literatura chicana, que pasó por varias etapas en su evolución. Algunos lo ubican en la época de la conquista española y otros refieren su primera aparición a los siglos XIX y XX:

En las crónicas y en las historias de los primeros colonizadores se fundamentan los relatos chicanos un ejemplo es Naufragios 1542, de Álvar o Álvaro Núñez Cabeza de Vaca. Otros afirman que con la aparición de poemas, cuentos y otros textos en publicaciones estadounidenses, durante los siglos XIX y XX se gesta un movimiento literario diferente al que se hacía en esa época, cuya manifestación implica una afirmación identitaria frente al otro. (Portes, 2006, p. 188)

Después de la guerra, los ciudadanos mexicanos residentes en los territorios conquistados tenían la libertad de quedarse o dejar la tierra. La mayoría optó por quedarse. Para que éstos recibieran la ciudadanía, tendrían que aprender y hablar la lengua inglesa. Pero el español seguía ser mantenido entre el pueblo por la presencia y la construcción de numerosos periódicos. Como resultado de todo lo que se ha mencionado, nació la literatura chicana que pudo sobrevivir y está en desarrollo en nuestros días.

Este clima era muy adecuado para el desarrollo de la literatura chicana, reflejando los sentimientos de esa población que se consideraba extranjera en su propia tierra. Por otra parte, era una manera para saber lo que pasa en el otro lado de la patria y conservar las costumbres mexicanas.

Dicha literatura también se desarrolló gracias al esfuerzo de un grupo de escritores y críticos chicanos que intentaban preservar sus orígenes y su denuncia de actitudes relacionadas con las xenofobias de las que, ellos mismos son víctimas. La literatura chicana rompió con la unicidad de la literatura americana pura. Es una mezcla de dos culturas que procede de un escritor que casi pertenece a dos países y dos culturas diferentes. Esto se considera el fruto de la migración que les permite pertenecer a dos sociedades diferentes.

Los años 60 eran generalmente años de caos y cambios sociales, entre ellos, la pérdida de igualdad y derechos de los negros. En los años 60 también ocurrieron varios cambios en la historia de la literatura chicana. 
Ya que se formó el movimiento chicano cuyo papel era hablar por el nombre de los chicanos y proteger sus derechos en EE. UU. De ahí, durante los años sesenta el significado del término se cambió para indicar al movimiento político que, a su vez, lucha para obtener los derechos de los latinos.

Chicano no es un término que se creara durante los años 60 como erróneamente afirman Penfield y Ornstein-Galicia (2018: lo que surgió fue su nuevo significado en los Estados Unidos. Fue en los años 60 y siguiendo el movimiento de derechos civiles que azotó el mundo cuando se cogió esta palabra y, dotándola de una carga positiva de identidad y orgullo, se utilizó como estandarte del movimiento político de la Raza para luchar por los derechos civiles y por una identidad propia de los hispanos. (Ornstein, 2018, p. 17)

Dicho movimiento conocido como "La Causa", uno de sus resultados fue la creación de una conciencia chicana, cuya producción era en el ámbito del arte, del teatro y del cine con el fin de presentar una literatura chicana, dirigida al lector chicano, ya en inglés o en español, ya en las dos lenguas y publicada casi siempre en casas editoriales chicanas en ediciones bilingües. Había algunas obras maestras que impulsaron este tipo literario.

El impulso inicial de la creación de esa nueva literatura se debe, sin duda alguna, a los poetas Rodolfo Gonzales -autor del poema épico "Yo soy Joaquín” (1967)- a Alarista. Ricardo Sánchez, José Montoya; en el teatro, a Luis Valdez y los organizadores del Teatro Campesino en 1965 durante la confrontación entre el sindicato de campesinos - organizado por César Chávezy los patrones. Valdez todavía usa el inglés, pero ya entreteje palabras en español sacadas del habla popular, ya sea del barrio, del lenguaje de los pachucos. (Ornstein, 2018, p. 15)

Los exiliados también participaron con su producción literaria. Había unos chicanos que escribieron para dar a conocer su cultura de origen a los estadounidenses.

Otros escritores de ascendencia mexicana nacidos en los Estados Unidos, o residentes en el país desde temprana edad, escribían en inglés bajo la influencia de modelos anglosajones. María Cristina Mena y Joscphina Niggli representan un caso especial. Ambas nacidas en México. Pero residentes en Estados Unidos desde la adolescencia, escribieron cuentos y novelas en inglés sobre temas mexicanos, con el objeto de dar a conocer su país de origen a los norteamericanos. (Leal, 1998, p. 14)

A finales de los años ochenta, la literatura fronteriza se conoció con el 
nombre de la narrativa del desierto por la gran influencia de la existencia del desierto que separa los dos países. A finales de los años ochenta, a la literatura de la frontera se le denominó la narrativa del desierto, y se contaba con cinco escritores reconocidos: Gerardo Cornejo (1937), de Sonora; Jesús Gardea (1939 [-2000]), de Chihuahua; Ricardo Elizondo (1950), etc. (Rodríguez, 2010, p.36).

Los temas que se narraban en esa época eran reflejo del aumento del flujo migratorio. Ya que se toman temas como la nostalgia al lugar de origen porque la mayoría no nacieron en baja California. Según Trujillo, esto motivó que algunos escritores "Se lanzaran al ruedo de la literatura con textos de nostalgia al solar nativo" (Muñoz, 2006). La incorporación de los jóvenes migrantes enriqueció ese tipo de literatura. Muchos de estos jóvenes eran exiliados españoles. Algunos eran poetas y otros periodistas.

El escritor más importante de este grupo es sin duda el poeta y periodista Jesús Sansón Flores (Morelia, Michoacán, 1909-Guadalajara, Jalisco, 1966), autor de Puños en alto (1932), El niño proletario (1936), Canción del odio (1938), Bajo el sol de España (1939), Hampa (1941), El camino perdido (1954) y la edición póstuma de Soplo de rebelión (1977). (Portes, 2006, p. 208)

Las obras de esa generación de escritores tuvieron gran valor entre los lectores y los críticos por su personalidad propia y por reflejar la realidad tal como es. Por eso, al revés de los antecedentes, se desarrolló la prosa que empezó a dominar la producción literaria. Tanto en la literatura fronteriza como en la chicana, aparece la influencia de la lengua del país acogida respecto a los chicanos y el país de los sueños respecto a los fronterizos, lo que resulta al final una mezcla entre dos lenguas para ofrecer el espanglés o el espanglish. "En ambos casos, es un estilo propio de expresión fronteriza utilizado por varios escritores, que da lugar a un lenguaje híbrido conocido como espanglish o espanglés" (Rodríguez Ortiz, 2008, p.132). Entonces, la lengua se considera un factor común entre los dos tipos de la literatura chicana y la fronteriza.

\section{Modelos}

Una de las figuras más repetidas en la literatura chicana es el protagonista trabajador o el joven que pertenece a la clase pobre que está buscando una vida digna para su familia y para él. El barrio también es uno de los espacios recurrentes en la literatura chicana junto con temas como la 
búsqueda de identidad, la emigración y los problemas socioeconómicos. En los barrios que dibujan los novelistas siempre está presente la herencia y las tradiciones mexicanas.

La primera obra es El pocho 1959. "De lo que no parece haber duda es del hecho de que la novela chicana por excelencia nació con el Pocho (1959) de José Antonio Villareal" (Rodríguez Ortiz, 2008). La prosa trataba de varios temas: históricos, las primeras relaciones entre gringos y mexicanos, los problemas urbanos, la educación de los niños, la tradición indígena y las contradicciones de la sociedad.

Uno de los ejemplos claros de la literatura chicana es El corrido de Dante de Eduardo Gonzales Viaña. ${ }^{2}$ Es el testimonio ficticio del inmigrante mexicano indocumentado. Como indica el título de la novela, el mejicano Dante Celestino, emigrado a Estados Unidos junto con su esposa Beatriz, con la que se rencuentra tras diez largos años, aventura que nos recuerda de la novela bizantina. También se plantea el tema del narcotráfico por la corruptela de los coyotes que ayudan a los inmigrantes a cruzar Río Grande. Una vez que logran instalarse en el pequeño pueblo de Mount Ángel (Oregón) y tener a Emma, Beatriz muere y hace prometer a Dante que preparará a su hija una fiesta de quinceañera que es el inicio de la novela. Antes de que concluya la reunión, aparece una banda de moteros capitaneada por un joven que parece haber acordado su aparición con Emma, la cual se escapa con él y no deja a su padre más que una carta

\footnotetext{
${ }^{2}$ Eduardo González Viaña nació en Chepén, La Libertad (Perú). Su infancia y adolescencia transcurrieron en el puerto de Pacasmayo. Estudió derecho y realizó sus estudios doctorales de Literatura en la Universidad de Trujillo. Asimismo, se especializó en Lingüística y Literatura en España y en etnología en L'école des Hautes Etudes en Sciences Sociales de París. Además, el periodismo fue una actividad practicada todo el tiempo. Desde la década del 90, González Viaña reside en los Estados Unidos trabajando como catedrático en las universidades de Berkeley y de Oregón. Igualmente, es importante destacar que se ubica entre los escritores peruanos más exitosos que radican en el extranjero. Entre sus variados galardones que ha recibido figuran: el Premio Nacional de Cultura 1972 (Perú), Premio Internacional Juan Rulfo de 1999, Premio Latino de Literatura de 2000 (EE. UU.), y el Premio Internacional Latino de Novela, en la Reunión Anual del Libro Latino, (EE. UU.) con la novela El corrido de Dante." Ha recibido varios premios importantes, como el Juan Rulfo para el cuento (1999) y el prestigioso Premio Latino (2007) por la novela mencionada. La mayoría de sus obras tratan de la frontera y la migración internacional y la vida de los hispanos en Estados Unidos (Moscoso, 2009).
} 
(llena de anglicismos). Dante, debido a su cultura de origen no comprende las exaltadas demandas de libertad de una chica tan joven, cosa permitida por la ley estadounidense.

La novela es muy auténtica para expresar el tipo de la literatura chicana por varias razones. Primero, está escrita por un escritor latino residente en Estados Unidos. Segundo, narra el sufrimiento de un protagonista mexicano y otro gran grupo de latinos en Estados Unidos. Tercero, la obra está llena de anglicismo. Cuarto, el paisaje de la obra es Estados Unidos, especialmente los lugares donde residen latinos. Uno de los ejemplos importantes de la literatura fronteriza es La frontera de Cristal (1995) del escritor Carlos Fuentes ${ }^{3}$ La novela se compone de nueve cuentos. Éstos confirman distintos puntos de vista de una misma historia en torno a la frontera entre México y Estados Unidos. Reflejan también la pluralidad de formas de vida e ideologías del inmigrante mexicano en Estados Unidos. Por otra parte, se afirma en la contraportada: "En esta novela (a través de nueve cuentos) Fuentes reproduce la separación que se ha dado entre México y Estados Unidos a lo largo de 200 años"3 (Fuentes, 1995). El personaje central de la novela es el ambicioso muy rico Leonardo Barroso, un empresario mexicano, director de fábricas maquiladoras en ciudad Juárez y contratista de obreros mexicanos para trabajar en ciudades norteamericanas. Leonardo Barroso es el personaje presente en los nueve textos.

La novela trata la historia de varios inmigrantes en Estados Unidos Benito Ayala (un bracero), Dan Polonski (un guarda de frontera de origen polaco), Margarita Barroso (inspectora de una maquiladora en Ciudad Juárez), Serafín Romero (unex-pepenador del Distrito Federal convertido en un maleante tipo Robin Hood en la zona fronteriza), Mario Islas (un

\footnotetext{
${ }^{3}$ Carlos Fuentes (1928-2012) fue un escritor, intelectual y diplomático mexicano, uno de los autores más destacados de su país y de las letras hispanoamericanas. Recibió, entre otros, el Premio Rómulo Gallegos en 1977, el Cervantes en 1987 y el Príncipe de Asturias de las Letras en 1994. Fue nombrado gran oficial de la Legión de Honor en 2003 y en 2009 caballero gran cruz de la Orden de Isabel la católica. Fue nombrado miembro honorario de la Academia Mexicana de la Lengua en agosto de 2000. A raíz de ser hijo de diplomático, vivió gran parte de su vida en varios países uno de estos era Estados Unidos, como consecuencia escribió novelas que tratan temas de la relación mexicana/estadounidense como El gringo viejo (1985) y La frontera de cristal (1995).
} 
oficial de frontera chicano), Eloíno (un espalda mojada), José Francisco (un motociclista artista e idealista) y Gonzalo Romero (que se dedica al coyotaje). La novela se ve como un buen ejemplo de la literatura chicana. Ya que la novela está escrita por un escritor mexicano residente en México. Muchas acciones ocurren en la frontera o narran la historia de personajes quienes están en la frontera entre Estados Unidos y México. Además, los nueve cuentos presentan varios símbolos de la frontera como el de la muerte, la pobreza, la violencia, la nostalgia o la decadencia de México.

La novela encarna también el conflicto que está en la frontera y los sufrimientos de los personajes para llegar al otro lado de la frontera. El destino de los personajes va a estar determinado en mayor o menor grado por su posición y distancia con respecto a la frontera mexicanoestadounidense. Las acciones se desarrollan en pasaje fronterizo, que describe el desierto de Chihuahua y Sonora, el río Bravo y el muro entre los dos países.

\section{Conclusiones}

Para concluir, la literatura chicana y la fronteriza son tipos de literatura desarrolladas a lo largo del tiempo a causa del flujo migratorio que está aumentando por causa de las condiciones sociales y políticas de Estados Unidos. Aunque la literatura chicana y la fronteriza tienen mucho que ver entre sí, sin embargo, hay algunas diferencias entre ellas.

El escritor chicano es un autor que escribe casi en inglés, pero que utiliza imágenes mexicanas con el objeto de darle a su obra un matiz original, pero al mismo tiempo, la literatura chicana se escribe en español, o en inglés o en mezclas de las lenguas. Mientras que la literatura fronteriza se escribe en español. En los dos tipos de literatura hay predominio del espanglish. No se sabe con certeza dónde se escribe ni dónde se publica. Los dos tipos de literatura se consideran un campo fértil para muchos nuevos estudios por el cambio duradero de la demografía del mundo y sus resultados.

\section{Referencias}


Aranda Oller, L. V. (2002). La alternancia lingüística en la literatura chicana: Una interpretación desde su contexto sociohistórico. Servicio de Publicaciones.

Arévalo Fernández, A. (2010). El uso del dialecto spanglish como recurso para el rescate de la otredad en Mayan Drifter de Juan Felipe Herrera. Trabajo de graduación para aspirar al grado de Mágister en traducción. Universidad Nacional.

Augé, M. (2006). Los no lugares. Espacio del anonimato. Una antropología de la sobre modernidad. Gedisa.

Barboto, L. (1999). El Tratado de Guadalupe Hidalgo. Alias.

Cardenas, D. (1970). Dominant Spanish dialects spoken in the United States. Center for applied linguistics.

Del Castillo, R. G. (1990). The treaty of Guadalupe Hidalgo: A legacy of conflict. University of Oklahoma Press.

Fuentes, C. (1995). La frontera de cristal. Santana.

Hudson-Edwards, A. and Bills, G. (1980). Intergenerational language shift in an Albuquerque barrio. In E. Blansitt \& R. Tescher (Eds.), A Festschrift for Jacob Ornstein (pp. 139-158). Newbury House.

Leal, L. (1998). La presencia del español en la literatura chicana. Tesis doctoral. Universidad de California.

Moscoso, M. (2009). Un corrido silencios. El corrido de Dante de Eduardo González Viaña. Tesis doctural. Universidad Católica Sedes Sapientiae.

Muñoz, G. (2006). Allá en el norte grande, allá donde escribía. Acequias, 3(34), 63-78.

Ornstein, J. (2018). Sociolinguistics and the study of Spanish and English language varieties and their use in the U.S. southwest (with a proposed plan of research). In J. Ornstein-Galicia, F. Hensey \& D. Foster (Eds.), Three essays on linguistic diversity in the Spanish-speaking world (pp. 9-46). De Gruyter Mouton. https://doi.org/10.1515/9783111358727-002

Portes, A. (2006). La nueva nación latina: Inmigración y la población hispana de los Estados Unidos. Revista Española de Investigaciones Sociológicas (REIS), 116(1), 55-96.

Rodríguez Ortiz, R. (2008). Disidencia literaria en la frontera México-Estados Unidos. Andamios, 5(9), 113-137.

Rodríguez, G. S. (2010). La frontera norteña femenina: Transgresión y resistencia identitaria en Esalí, Conde y Rivera Garza. Arizona State University Press.

Tabuenca Córdoba, M. S. (1997). Aproximaciones críticas sobre las literaturas de las fronteras. Frontera norte, 9(18), 85-110.

Torres Sauchett, M. (2013). Recreación del espacio fronterizo: Imágenes en la literatura de la frontera en Baja California, México. Tesis doctoral. Universidad Complutense de Madrid. 